\title{
TOPIC: HOW DO WE FLY?
}

\section{Binh $\mathrm{Ha}^{1}$}

${ }^{1}$ Affiliation not available

June 1, 2021

Time: 50 minutes

Grade: $11-14$

Overview: Students will learn different mechanics that help airplanes take off from the ground and apply them by building their own miniature airplanes.

\section{Vocabulary:}

\begin{tabular}{ll}
\hline Mass & Cross section \\
\hline Propeller & Surface area \\
Pressure & \\
Lift Force & \\
\hline
\end{tabular}

\section{Objectives:}

Students can learn and apply basic concepts in physics.

Students will learn about basic parts of an airplane and how to build one.

\section{Required Project Material:}

- Wood stick.

- DC motor set.

- Battery pack 2A (with switch).

- Mini propeller.

- Model

\section{Multimedia Resources:}

None

\section{Before lesson/ Background information}

Showing a demonstration of lift force using a sheet of paper.

\section{The Lesson}

\section{Activity 1: Demonstration activity (10 minutes)}

Teacher will divide the students into each group (4-5 students per group) 
The teacher gives each group 1 thin flat sheet of paper, asking:

Put the flat paper under your mouth, if we blow hard on the top surface of the paper, do you have any prediction about the paper, the paper will hang down or be pushed up?

After making prediction, the groups made the request to blow the paper of the teacher and commented on the phenomenon that happened.

Teacher commented and explained the phenomenon: Because when we blow the paper, the air flow on the top side of the paper moves quickly, causing the pressure on the surface of the paper to decrease, besides the airflow below the paper. Standing still or moving slowly, the pressure is greater than the top, causing the other end of the paper to push up.

$F=p . S(\mathrm{~N})$

In which: $\mathrm{F}$ is the lift force of the aircraft's wing $(\mathrm{N})$

$p$ is the difference in pressure between the bottom and top surface of the wing $\left(\mathrm{N} / \mathrm{m}^{2}\right)$.

$\mathrm{S}$ is the total cross section of the wing $\left(\left(\mathrm{m}^{2}\right)\right.$

\section{Activity 2: Building a propeller airplane (40 minutes)}

1. Teacher reintroduces the necessary equipment and tools to make the model of the airplane.

2. Teacher distributes equipment and materials to groups, shows the lecture on how to mount the airplane model

3. Each groups are required to build the model airplane according to the model

4. As soon as they finished their model, each groups are required to think about how to make their airplanes model take off from the ground using the concepts learned from the class

Homework: Students are required to make a list of problems that prevent their aircraft model from flying 